\title{
Effect of storage temperature on texture, polymorphic structure, bloom formation and sensory attributes of filled dark chocolate
}

\begin{abstract}
The effects of 18 and $30^{\circ} \mathrm{C}$ storage temperatures on texture, polymorphic structure, bloom formation and sensory attributes of dark chocolate, stored for 8 weeks were studied. Results showed that storage at $18^{\circ} \mathrm{C}$ for 8 weeks, significantly retarded changes in filled chocolates; the chocolates were free from bloom during the storage period. In contrast, at $30^{\circ} \mathrm{C}$ there was an increase in the rate of fat migration and rate of change of C36 and C50, and also a decrease in texture and the polymorph structure in the coating changed to 6 and $6 \mathrm{Nj}$ polymorphs. However, the chocolates bloomed in the third week of storage (2 cycles). Sensory evaluation indicated that, storage at $18^{\circ} \mathrm{C}$ is better than $30^{\circ} \mathrm{C}$, and desiccated coconut gives a pleasant flavour to the chocolate.
\end{abstract}

Keyword: Storage temperture; Texture; Polymorphic structures; Bloom formation; Sensory attributes; Filled dark chocolate 